\title{
Synthesis, Crystal Structure and Vibrational Spectra of $\mathrm{Mg}_{2}\left[\mathrm{BN}_{2}\right] \mathrm{Br}$ : A New Magnesium Nitridoborate Halide with Discrete $[\mathbf{N}-\mathbf{B}-\mathbf{N}]^{3-}$ Groups
}

\author{
Ilkin Kokal, ${ }^{[a, b]}$ Mehmet Somer, ${ }^{[b]}$ Lev Akselrud, ${ }^{[c]}$ Peter Höhn, ${ }^{*}[\mathrm{~d}]$ and \\ Wilder Carrillo-Cabrera*[d]
}

\author{
In Memory of Professor Hans-Georg von Schnering
}

Keywords: Nitridoborate halides; Magnesium; Boron; IR spectroscopy; Raman spectroscopy

Abstract. $\mathrm{Mg}_{2}\left[\mathrm{BN}_{2}\right] \mathrm{Br}$ was prepared from stoichiometric mixtures of the respective binary components $\mathrm{Mg}_{3} \mathrm{~N}_{2}, \mathrm{MgBr}_{2}$ and $\mathrm{BN}$ in sealed niobium ampoules placed in evacuated silica tubes at $1473 \mathrm{~K}$. The monoclinic crystal structure $(C 2 / c$ (no. 15$) ; a=9.1509(3) \AA, b=$ 6.6209(3) $\AA, c=6.4756(2) \AA, \beta=109.353(3)^{\circ}$ and $Z=4$ ) was determined from powder data. The crystal structure is characterized by cationic $3^{2} .4 .3 .4$ nets of magnesium and anionic hexagonal closed packed $3^{6}$ nets of six-connected nodes occupied by $[\mathrm{N}-\mathrm{B}-\mathrm{N}]^{3-}$ units and $\mathrm{Br}^{-}$ anions. Both types of planar nets alternate along the [100] direction. The packing of such incoherent nets results in a monoclinic symmetry, which is a compromise for a structure built up from rod-like [N-B$\mathrm{N}]^{3-}$ units and spherical bromine and magnesium atoms. Bond length and bond angle for the $[\mathrm{N}-\mathrm{B}-\mathrm{N}]^{3-}$ unit are $d(\mathrm{~B}-\mathrm{N})=1.354(2) \AA$ and $\angle(\mathrm{N}-\mathrm{B}-\mathrm{N})=177.1(9)^{\circ}$, respectively.

Vibrational spectra were analyzed based on the $D_{\infty}$ symmetry of the relevant $[\mathrm{N}-\mathrm{B}-\mathrm{N}]^{3-}$ moieties, considering the site symmetry splitting. The results are discussed in context with those of the known members of the magnesium dinitridoborate halide series, $\mathrm{Mg}_{2}\left[\mathrm{BN}_{2}\right] \mathrm{Cl}$ and $\mathrm{Mg}_{8}\left[\mathrm{BN}_{2}\right]_{5} \mathrm{I}$.

$\mathrm{Mg}_{2}\left[\mathrm{BN}_{2}\right] \mathrm{Br}$ could be identified by both X-ray diffraction and vibrational spectroscopic methods.

In the following, we report on the synthesis, crystal structures and the vibrational spectra of the novel compound $\mathrm{Mg}_{2}\left[\mathrm{BN}_{2}\right] \mathrm{Br}$. been synthesized and structurally characterized: $M_{2}\left[\mathrm{BN}_{2}\right] X$ $(M=\mathrm{Mg}, \mathrm{Ca}, \mathrm{Sr} ; X=\mathrm{F}, \mathrm{Cl}), \mathrm{Sr}_{2}\left[\mathrm{BN}_{2}\right] \mathrm{I}, \mathrm{Ba}_{8}\left[\mathrm{BN}_{2}\right]_{5} \mathrm{~F}^{[1-5]}$ The compounds can be regarded as double salts, containing both isolated anions $\left[\mathrm{BN}_{2}\right]^{3-}$ and $X^{-}$as anionic structural units. Recently, we have reported on the respective magnesium phases $\mathrm{Mg}_{2}\left[\mathrm{BN}_{2}\right] \mathrm{Cl}$ and $\mathrm{Mg}_{8}\left[\mathrm{BN}_{2}\right]_{5} \mathrm{I},{ }^{[6]}$ which are isostoichiometric but not isostructural with any of the nitridoborate halides mentioned above. Furthermore, the investigations have been extended to the quasi-ternary system $\mathrm{Mg}_{3} \mathrm{~N}_{2} / \mathrm{BN} / \mathrm{MgBr}_{2}$, in which the existence of a new phase with the composition

\footnotetext{
* Dr. P. Höhn

Fax: +49-351-4646-2260

E-Mail: hoehn@cpfs.mpg.de

* Dr. W. Carrillo-Cabrera

Fax: +49-351-4646-3002

E-Mail: carrillo@cpfs.mpg.de

[a] Inorganic Materials Chemistry

Eindhoven University of Technology

P.O. Box 513

5600 MB Eindhoven, The Netherlands

[b] Chemistry Department

Koç University

34450 Sariyer-Istanbul, Turkey

[c] Department of Inorganic Chemistry

Ivan Franko National University Lviv 79000, Ukraine

[d] Max-Planck-Institut für Chemische Physik fester Stoffe

Nöthnitzer Str. 40

01187 Dresden, Germany
}

\section{Results and Discussion}

\section{Crystal Structure}

The title compound $\mathrm{Mg}_{2}\left[\mathrm{BN}_{2}\right] \mathrm{Br}$ crystallizes in a new structure type (Pearson code $m C 24$ ). The crystal structure is characterized by the strictly separated discrete linear $[\mathrm{N}-\mathrm{B}-\mathrm{N}]^{3-}$ units $(d(\mathrm{~B}-\mathrm{N})=1.354(2) \AA]$ and $\mathrm{Br}^{-}$anions. The magnesium partial structure consists of $3^{2} .4 .3 .4$ cationic nets (topologically similar to those formed by uranium in tetragonal $\mathrm{U}_{3} \mathrm{Si}_{2}{ }^{[7]}$ ) parallel to (100) (Figure 1). The boron atoms of the $[\mathrm{N}-\mathrm{B}-\mathrm{N}]^{3-}$ units and the $\mathrm{Br}^{-}$anions build up hexagonal close packed $3^{6}$ anionic nets parallel to (100). Both kinds of ionic nets alternate along the [100] direction (Figure 2a). The packing of these two kinds of nets is incompatible in both the hexagonal or tetragonal system (Figure 2b), resulting in a monoclinic structure with distorted polyhedral environments around each anionic unit. This can be rationalized as a compromise for a structure built up from linear $[\mathrm{N}-\mathrm{B}-\mathrm{N}]^{3-}$ units and spherical bromine and magnesium atoms. 


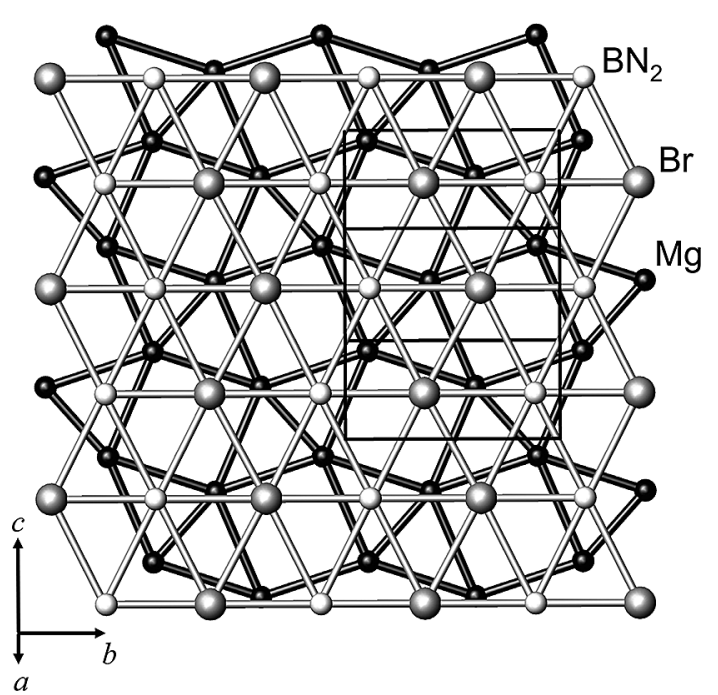

Figure 1. Illustration of the structure of $\mathrm{Mg}_{2}\left[\mathrm{BN}_{2}\right] \mathrm{Br}$, showing the cationic and anionic nets. Parallel to the (100) plane, the magnesium partial structure consists of $3^{2} .4 .3 .4$ nets (black colored, equivalent to those of uranium in tetragonal $\mathrm{U}_{3} \mathrm{Si}_{2}$ ). The boron atoms of the [N-B$\mathrm{N}]^{3-}$ units and the $\mathrm{Br}^{-}$anions form an anionic hexagonal close packed $3^{6}$ net (grey). Along [010] bromine and boron atoms appear overlapping.

(a)

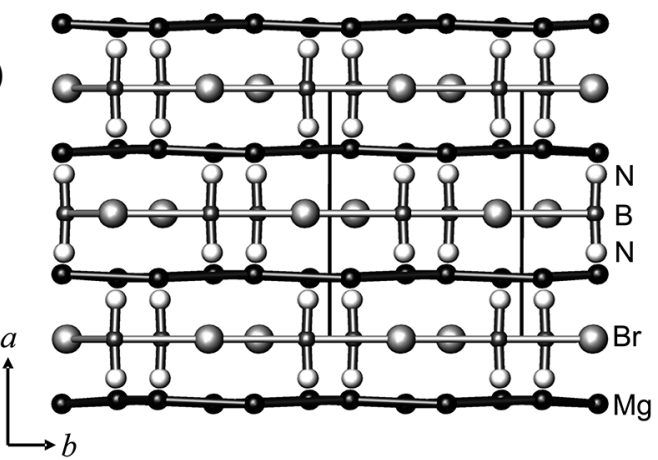

(b)

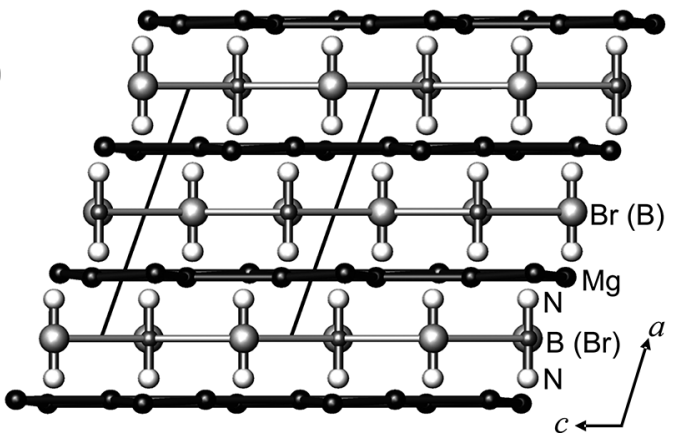

Figure 2. Projections of the $\mathrm{Mg}_{2}\left[\mathrm{BN}_{2}\right] \mathrm{Br}$ structure (a) along [001] and (b) along [010] directions. These two kinds of nets are incompatible with higher symmetry, resulting in a monoclinic structure which is a compromise for a structure built up from linear $[\mathrm{N}-\mathrm{B}-\mathrm{N}]$ units and spherical bromine and magnesium atoms.

Moreover, the bromine atoms form $4^{4}$ nets parallel to (001) (not shown in figures), in which two bromine atoms are connected by magnesium bridges $((d(\mathrm{Br}-\mathrm{Mg})=2.729(1)$,
3.017(1) $\AA$ ), forming puckered layers (not shown in the figures).

Each magnesium atom is surrounded by three nitrogen atoms $(d(\mathrm{Mg}-\mathrm{N})=2.0621(3)-2.085(3) \AA)$, two bromine atoms $(d(\mathrm{Mg}-\mathrm{Br})=2.895(1), 3.017(1) \AA)$ and another bromine atom at a longer distance $(d(\mathrm{Mg}-\mathrm{Br})=3.755(1) \AA)$. The $[\mathrm{N}-\mathrm{B}-\mathrm{N}]^{3-}$ unit has six magnesium atoms as next neighbors. The $\mathrm{Mg}_{6}$ coordination polyhedron around $[\mathrm{N}-\mathrm{B}-\mathrm{N}]^{3-}$ (Figure $3 \mathrm{a}$ ) is very distorted, resembling a twisted trigonal antiprism. The polyhedron around $\mathrm{Br}^{-}$(Figure 3b) is even more irregular consisting of four magnesium nearest neighbors $(d(\mathrm{Br}-\mathrm{Mg})=2.729(1)-$ $3.020(1) \AA)$ and two others at a longer distance $(d(\mathrm{Br}-\mathrm{Mg})=$ $3.755(1) \AA)$.
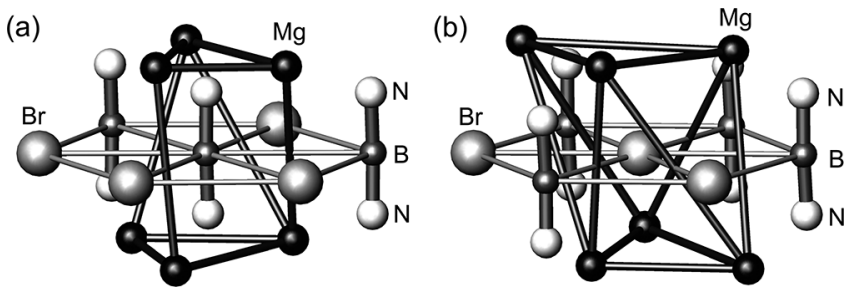

Figure 3. The $\mathrm{Mg}_{6}$ coordination polyhedra around (a) $[\mathrm{N}-\mathrm{B}-\mathrm{N}]^{3-}$ and (b) $\mathrm{Br}^{-}$anions in $\mathrm{Mg}_{2}\left[\mathrm{BN}_{2}\right] \mathrm{Br}$ correspond to very twisted trigonal antiprisms. The polyhedron (b) is more irregular than (a).

The building principles for the alkaline earth dinitridoborate halides $M_{2}\left[\mathrm{BN}_{2}\right] X(M=\mathrm{Ca}, \mathrm{Sr}, \mathrm{Ba} ; X=\mathrm{F}, \mathrm{Cl})$ were discussed in detail elsewhere. ${ }^{[2-6]}$ The most striking structural guideline in all these phases is the distinct separation between the substructures of the spherically shaped halide and the rod-like nitridoborate anions. Obviously, this principle can be realized in different arrangements so that almost each member of the $M_{2}\left[\mathrm{BN}_{2}\right] X$ series crystallizes in its own individual crystal structure. As a consequence, most of the known alkaline earth dinitridoborate halides are isostoichiometric but only rarely isostructural, e.g. $\mathrm{Ca}_{2}\left[\mathrm{BN}_{2}\right] X(X=\mathrm{F}, \mathrm{Cl}){ }^{[3]}$

Magnesium dinitridoborate halides show more or less the same building principles, as was discussed for the $M_{2}\left[\mathrm{BN}_{2}\right] X$ $(M=\mathrm{Ca}, \mathrm{Sr}, \mathrm{Ba} ; X=\mathrm{F}, \mathrm{Cl}, \mathrm{Br}, \mathrm{I}))$ series. The common structural units in the magnesium compounds are $\mathrm{Mg}_{6}$ trigonal prisms (or antiprisms), which are condensed to 3D frameworks in different ways. In all cases, trigonal prisms (or antiprisms) are centered by the $[\mathrm{N}-\mathrm{B}-\mathrm{N}]^{3-}$ anions and other voids in the frameworks by the $X^{-}$anions. The magnesium environment around $\mathrm{Cl}^{-}$is a highly distorted monocapped trigonal prism $(\mathrm{CN}=(5+1)+1)$. In the title compound, $\mathrm{Br}^{-}$ions are surrounded by six magnesium atoms forming a very distorted trigonal antiprism whereas in $\mathrm{Mg}_{8}\left[\mathrm{BN}_{2}\right]_{5} \mathrm{I}$ the iodide ion is occupying the center of a bicapped heptagonal prism $(\mathrm{CN}=14+$ 2) ${ }^{[6]}$ These findings suggest that the crucial criterion determining the crystal structure of the magnesium double salts is the radius and the space requirement (coordination sphere) of the respective halide anion. It is interesting to note that all attempts to synthesize magnesium dinitridoborates with mixed halides, such as $\mathrm{Mg}_{2}\left[\mathrm{BN}_{2}\right](\mathrm{Cl}, \mathrm{Br})$, failed up to now, yielding only phase mixtures of the pure quaternaries $\mathrm{Mg}_{2}\left[\mathrm{BN}_{2}\right] X(X=\mathrm{Cl}$, $\mathrm{Br})$. 


\section{Vibrational Spectra}

The vibrational spectra of $\mathrm{Mg}_{2}\left[\mathrm{BN}_{2}\right] \mathrm{Br}$ (Figure 4) are characterized by the linear $\left[\mathrm{BN}_{2}\right]^{3-}$ moieties with the idealized symmetry $D_{\infty h}$ for which the following four fundamentals are expected:

$$
\Gamma_{\mathrm{vib}}=v_{1}\left(\Sigma_{\mathrm{g}}\right)(\mathrm{R})+v_{2}\left(\Sigma_{\mathrm{u}}\right)(\mathrm{IR})+v_{3}\left(\Pi_{\mathrm{u}}\right)(\mathrm{IR}) .
$$

The existence of the symmetry center applies for the mutual exclusion, so that $v_{1}\left(\Sigma_{\mathrm{g}}\right)$ will be observed solely in the Raman spectrum whereas $v_{2}\left(\Sigma_{\mathrm{u}}\right)$ and double-degenerate $v_{3}\left(\Pi_{\mathrm{u}}\right)$ appear exclusively in the IR spectrum.

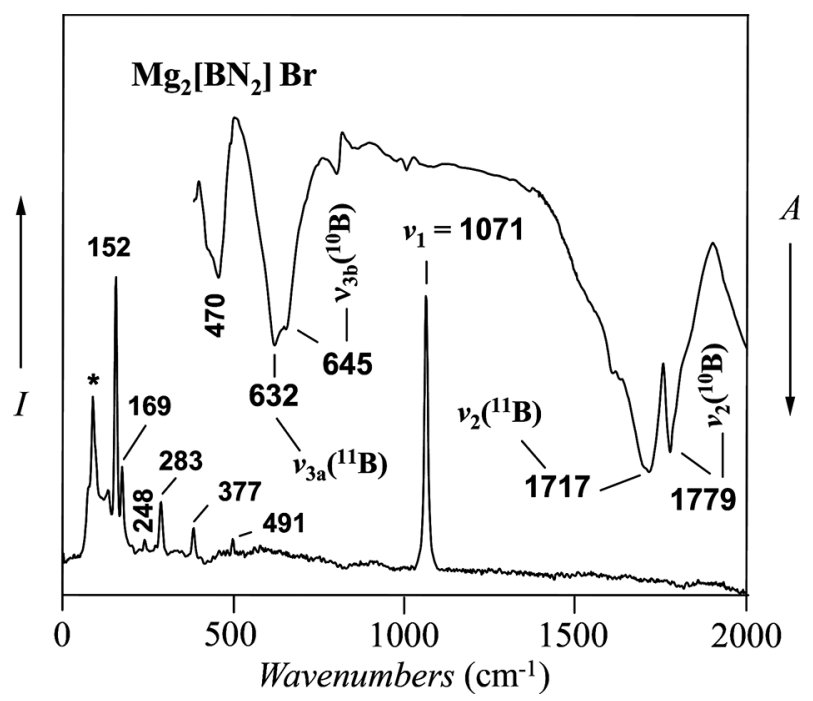

Figure 4. Vibrational spectra of $\mathrm{Mg}_{2}\left[\mathrm{BN}_{2}\right] \mathrm{Br}$. Intensity $I$ (Raman) in arbitrary units; absorption $A$ (IR) in \%. (*) Laser line.

In solid $\mathrm{Mg}_{2}\left[\mathrm{BN}_{2}\right] \mathrm{Br}$ the $\left[\mathrm{BN}_{2}\right]^{3-}$ groups center the site 2$C_{2}$, meaning that the selection rules for the free anion are no longer valid. As a consequence, the degeneracy for the deformation mode $\Pi_{\mathrm{u}}$ and the mutual exclusion for the free anion will be abolished in both spectra. Thus, $v_{3}\left(\Pi_{\mathrm{u}}\right)$ splits into $v_{3 \mathrm{a}}$ and $v_{3 \mathrm{~b}}$, whereas $v_{1}$ and $v_{2}$ remain observable mutually in Raman and IR spectra, respectively. But altogether, the deviation from the strict linearity is small allowing the assignment of the spectra in the $D_{\infty h}$ symmetry.

Only $v_{2}$ exhibits the expected ${ }^{10} \mathrm{~B} /{ }^{11} \mathrm{~B}$ isotope splitting (1717/ $1779 \mathrm{~cm}^{-1}$ ), whereas the weak ${ }^{10} \mathrm{~B}$ components of $v_{3}$ are completely obscured by the broad $v_{3 \mathrm{a}}$ and $v_{3 \mathrm{~b}}$ bands at 632 and $645 \mathrm{~cm}^{-1}$, respectively. The symmetric (N-B-N) stretch is registered as a very intense Raman band at $1071 \mathrm{~cm}^{-1}$. The remaining Raman lines at 491, 377, 283, 248, 169, and $152 \mathrm{~cm}^{-1}$ and the broad absorption band at $470 \mathrm{~cm}^{-1}$ are assigned to lattice modes.

Utilizing the measured wavenumbers, the $(\mathrm{B}-\mathrm{N})$ valence and bending force constants $f$ and $f_{\mathrm{D}}$, as well as the interaction force constant $f^{\prime}$ were calculated as $8.12,0.47,1.34 \mathrm{~N} \cdot \mathrm{cm}^{-1}$, respectively. The value for the $(\mathrm{B}-\mathrm{N})$ valence constant is in good agreement with the effective charge model reported elsewhere, ${ }^{[8,9]}$ i.e. the lower the effective charge of the $\left[\mathrm{BN}_{2}\right]^{3-}$ moieties, the higher the $(\mathrm{B}-\mathrm{N})$ valence frequencies and force constants. Hence, the comparatively higher electronegativity of chlorine is expected to give rise to more reduced values, and iodine, in turn, to a higher effective negative charge on $\left[\mathrm{BN}_{2}\right]^{3-}$. In this sense, the trend for the series of the magnesium dinitridoborate halide salts with $f(\mathrm{~B}-\mathrm{N})=8.24 \mathrm{~N} \cdot \mathrm{cm}^{-1}$ $\left(\mathrm{Mg}_{2}\left[\mathrm{BN} \mathrm{N}_{2}\right] \mathrm{Cl}\right),{ }^{[6]} 8.12 \mathrm{~N} \cdot \mathrm{cm}^{-1}\left(\mathrm{Mg}_{2}\left[\mathrm{BN} \mathrm{N}_{2}\right] \mathrm{Br}\right)$ harmonizes well with the effective charge model. The last member of this family, $\mathrm{Mg}_{8}\left[\mathrm{BN}_{2}\right]_{5} \mathrm{I}$, is an interesting exception with $f(\mathrm{~B}-\mathrm{N})=8.30$ $\mathrm{N} \cdot \mathrm{cm}^{-1}$. The unexpected high value of the force constant for the iodide salt is due to the low $\mathrm{I}:\left(\mathrm{BN}_{2}\right)$ ratio $(1: 5)$; i.e. the compound "behaves" almost like the "pure" magnesium dinitridoborate: $f\left(\mathrm{Mg}_{3}\left[\mathrm{BN}_{2}\right] \mathrm{N}\right)=8.31 \mathrm{~N} \cdot \mathrm{cm}^{-1} \cdot{ }^{[10]}$

\section{Conclusions}

$\mathrm{Mg}_{2}\left[\mathrm{BN}_{2}\right] \mathrm{Br}$ was obtained as a microcrystalline powder. The compound crystallizes in a new structure type. Predominant structural units are isolated rod-like $\left[\mathrm{BN}_{2}\right]^{3-}$ and spherical $\mathrm{Br}^{-}$ moieties which are embedded in a cationic matrix formed by condensed very distorted (twisted) $\mathrm{Mg}_{6}$ trigonal prisms. The vibrational spectra show the three modes characteristic for the $[\mathrm{N}-\mathrm{B}-\mathrm{N}]^{3-}$ groups with the expected site symmetry and isotope splitting effects.

\section{Experimental Section}

\section{Synthesis}

$\mathrm{Mg}_{2}\left[\mathrm{BN}_{2}\right] \mathrm{Br}$ was synthesized from stoichiometric mixtures of the binaries $\mathrm{Mg}_{3} \mathrm{~N}_{2}, \mathrm{BN}$ and $\mathrm{MgBr}_{2}$ in arc-welded niobium ampoules, placed in evacuated silica tubes. The samples were heated during $6 \mathrm{~h}$ to 1473 $\mathrm{K}$, annealed for $24 \mathrm{~h}$ and cooled down to room temperature within the next $24 \mathrm{~h}$. The reaction products were single-phase colorless microcrystalline powders. All attempts to obtain suitable single crystals of $\mathrm{Mg}_{2}\left[\mathrm{BN}_{2}\right] \mathrm{Br}$ failed up to now, despite several significant variations of the synthesis conditions, such as increase of reaction temperature and annealing time. Also an excess of $\mathrm{MgBr}_{2}$ had no influence on the quality of the crystals, as was reported before. ${ }^{[5]}$

$\mathrm{Mg}_{2}\left[\mathrm{BN}_{2}\right] \mathrm{Br}$, as well as the starting materials $\mathrm{Mg}_{3} \mathrm{~N}_{2}$ and $\mathrm{MgBr}_{2}$ are air and moisture sensitive. Therefore, all handling with starting materials and products had to be performed under inert conditions; i.e. glove box, $\mathrm{N}_{2} ; \mathrm{O}_{2}$ and $\mathrm{H}_{2} \mathrm{O} \leq 1 \mathrm{ppm}$.

\section{X-ray Powder Investigations}

The X-ray diffraction pattern of $\mathrm{Mg}_{2}\left[\mathrm{BN}_{2}\right] \mathrm{Br}$ was obtained with a Huber G670 Imaging- Plate Guinier Camera using $\mathrm{Cu}-K_{\alpha 1}$ radiation. Indexing led to a monoclinic unit cell. The structure was solved using the WinCSD program package ${ }^{[11]}$ and refined (Rietveld method) using the GSAS program. ${ }^{[12]}$

The crystallographic data and the conditions for data collection and refinement for $\mathrm{Mg}_{2}\left[\mathrm{BN}_{2}\right] \mathrm{Br}$ are summarized in Table 1. Table 2 and Table 3 contain the atomic coordinates, displacement parameters and the main bond lengths and bond angles, respectively. Figure 5 shows the graphical presentation of the Rietveld refinement. 
Table 1. Results of Rietveld refinements for $\mathrm{Mg}_{2}\left[\mathrm{BN}_{2}\right] \mathrm{Br}$.

\begin{tabular}{ll}
\hline Compound & $\mathrm{Mg}_{2}\left[\mathrm{BN}_{2}\right] \mathrm{Br}$ \\
\hline Crystal system & monoclinic \\
Crystal color, shape & colorless microcrystalline powder \\
Space group & $C 2 / c($ No.15) \\
$Z$ & 4 \\
$a / \AA$ & $9.1509(3)$ \\
$b / \AA$ & $6.6209(3)$ \\
$c / \AA$ & $6.4756(2)$ \\
$\beta /{ }^{\circ}$ & $109.353(3)$ \\
$V / \AA^{3}$ & $370.17(3)$ \\
$d_{\mathrm{x}} / \mathrm{g} \cdot \mathrm{cm}^{-3}$ & $3.004(1)$ \\
Diffractometer & Huber G670 \\
Detector & Image Plate \\
Monochromator & $\mathrm{Germanium}$ \\
Radiation, Wavelength $/ \AA$ & $\mathrm{Cu}-K_{\alpha 1}, 1.540598$ \\
$2 \theta$ range $/{ }^{\circ}$ & $6.03-100$ \\
Program structure method & Rietveld \\
Program for structure solution & WinCSD \\
and refinement & $\mathrm{GSAS} \mathrm{S}^{[12]}$ \\
Refined parameters & 16 \\
$R_{\text {int }} R_{\text {prof }}$ & $0.0679,0.0916$ \\
\hline
\end{tabular}

Table 2. Atomic coordinates and displacement parameters $/ \AA^{2}$ for $\mathrm{Mg}_{2}\left[\mathrm{BN}_{2}\right] \mathrm{Br}$. Standard deviations are given in parentheses.

\begin{tabular}{llllll}
\hline Atom & Site & $x$ & $y$ & $z$ & $U_{\text {iso }} / U_{\text {eq }}$ \\
\hline $\mathrm{Mg}$ & $8 f$ & $0.2419(1)$ & $0.1035(2)$ & $0.6634(1)$ & $0.0165(4)$ \\
$\mathrm{B}$ & $4 e$ & 0 & $0.1178(15)$ & $1 / 4$ & $0.0211(17)$ \\
$\mathrm{N}$ & $8 f$ & $0.1567(2)$ & $0.1126(4)$ & $0.3184(3)$ & $0.0118(7)$ \\
$\mathrm{Br}$ & $4 e$ & 0 & $0.63113(15)$ & $1 / 4$ & $0.0183(2)^{\mathrm{a})}$ \\
\hline
\end{tabular}

a) Anisotropic displacement parameters $/ \AA^{2}: U_{11}=0.0040(3), U_{22}=$ $0.0285(4), U_{33}=0.0229(4), U_{13}=0.0069(3), U_{12}=U_{23}=0$.

Table 3. Selected atomic distances $/ \AA$ and bond angles $/^{\circ}$ in $\mathrm{Mg}_{2}\left[\mathrm{BN}_{2}\right] \mathrm{Br}$ with their multiplicity. Standard deviations are given in parentheses.

\begin{tabular}{|c|c|c|c|c|c|c|}
\hline \multirow{6}{*}{$\mathrm{Mg}_{-}$} & $\mathrm{N}$ & \multicolumn{2}{|l|}{$2.045(3)$} & \multirow{2}{*}{$\begin{array}{ll}\mathrm{N}-\mathrm{B} \\
\mathrm{Mg}\end{array}$} & \multicolumn{2}{|l|}{$1.354(2)$} \\
\hline & $\mathrm{N}$ & $2.082(3)$ & & & \multicolumn{2}{|l|}{$2.045(3)$} \\
\hline & $\mathrm{N}$ & \multicolumn{2}{|l|}{$2.109(2)$} & $\mathrm{Mg}$ & \multicolumn{2}{|l|}{$2.082(3)$} \\
\hline & $\mathrm{Br}$ & \multicolumn{2}{|l|}{$2.726(1)$} & $\mathrm{Mg}$ & \multicolumn{2}{|l|}{$2.109(2)$} \\
\hline & $\mathrm{Br}$ & \multicolumn{2}{|l|}{$3.020(1)$} & & & \\
\hline & $\mathrm{Br}$ & \multicolumn{2}{|l|}{$3.754(1)$} & & & \\
\hline \multirow[t]{4}{*}{ B- } & $\mathrm{N}$ & $1.354(2)$ & $2 \times$ & $\mathrm{Br}-\mathrm{Mg}$ & $2.726(1)$ & $2 \times$ \\
\hline & $\mathrm{Mg}$ & $2.855(1)$ & $2 \times$ & $\mathrm{Mg}$ & $3.020(1)$ & $2 \times$ \\
\hline & $\mathrm{Mg}$ & $2.861(5)$ & $2 \times$ & $\mathrm{Mg}$ & $3.754(1)$ & $2 \times$ \\
\hline & $\mathrm{Mg}$ & $2.902(6)$ & $2 \times$ & & & \\
\hline \multicolumn{4}{|c|}{$\angle(\mathrm{N}-\mathrm{B}-\mathrm{N})$} & \multicolumn{2}{|c|}{$177.1(9)^{\circ}$} & \\
\hline
\end{tabular}

\section{Vibrational Spectroscopy}

The FT-Raman measurements were performed on powdered samples sealed in pyrex tubes $(\varnothing=4 \mathrm{~mm})$ with a Bruker RFS $100 / \mathrm{S}$ spectrometer (Nd: YAG-Laser, $1064 \mathrm{~nm}, 200 \mathrm{~mW}$ ). The FT-IR spectra were recorded from $\mathrm{KBr}$ pellets using a Jasco FT-IR-600 spectrometer.

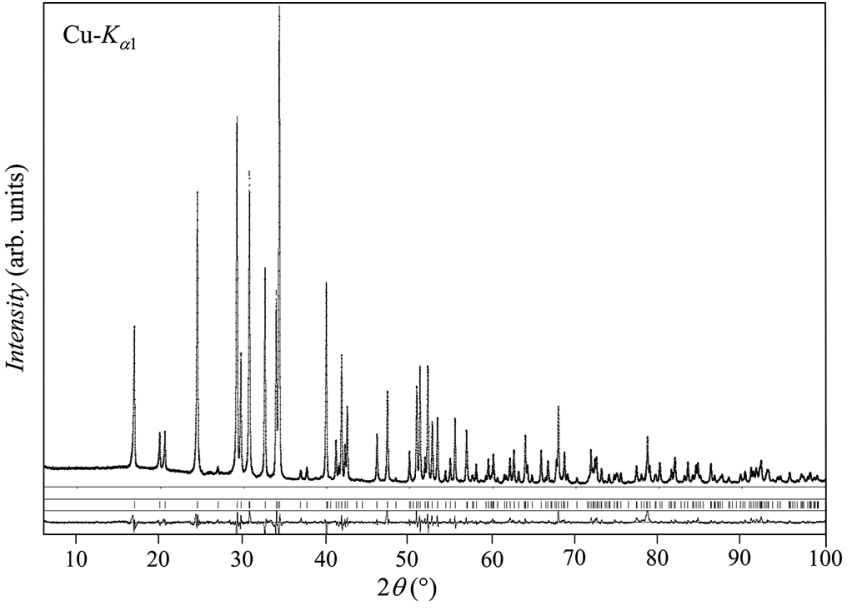

Figure 5. Superimposed observed and calculated X-ray powder patterns (upper part), Bragg peak positions (short vertical lines) and difference profile plot (lower part) from the full profile Rietveld refinement of $\mathrm{Mg}_{2}\left[\mathrm{BN}_{2}\right] \mathrm{Br}, \mathrm{Cu}-K_{\alpha 1}$ radiation. Intensity in arbitrary units.

\section{Acknowledgement}

Prof. Dr. von Schnering and his group significantly developed the systematic research on ternary and quaternary earth alkaline metal nitridoborates and their derivatives for more than 20 years. His contributions for the general understanding of the crystal structures of the $M^{\mathrm{I}} M^{\mathrm{II}}{ }_{4}\left[\mathrm{BN}_{2}\right]_{3}$ series $\left(M^{\mathrm{I}}=\mathrm{Li}, \mathrm{Na} ; M^{\mathrm{II}}=\mathrm{Mg}, \mathrm{Ca}, \mathrm{Sr}, \mathrm{Ba}, \mathrm{Eu}\right)$ were very important. The authors thank for his inspiring ideas and discussions.

\section{References}

[1] O. Reckeweg, H.-J. Meyer, Z. Naturforsch. 1997, 52b, 340-344.

[2] F. E. Rohrer, Dissertation, Eidgenössische Technische Hochschule, Zürich, 1997.

[3] F. E. Rohrer, R. Nesper, J. Solid State Chem. 1998, 135, 194200.

[4] F. E. Rohrer, R. Nesper, J. Solid State Chem. 1999, 142, 187191.

[5] F. E. Rohrer, R. Nesper, J. Solid State Chem. 1999, 142, 192 198.

[6] M. Somer, M. N. Kütükcü, R. Cardoso-Gil, H. Borrmann, W. Carrillo-Cabrera, Z. Anorg. Allg. Chem. 2004, 630, 1015-1021.

[7] W. H. Zachariasen, Acta Crystallogr. 1948, 1, 265-268.

[8] M. Somer, U. Herterich, J. Curda, W. Carrillo-Cabrera, A. Zürn, K. Peters, H. G. von Schnering, Z. Anorg. Allg. Chem. 2000, 626, 625-633.

[9] M. Somer, Ö. Yaren, O. Reckeweg, Yu. Prots, W. Carrillo-Cabrera, Z. Anorg. Allg. Chem. 2004, 630, 1068-1073.

[10] M. Somer, unpublished results.

[11] L. G. Akselrud, P. Y. Zavalli, Yu. N. Grin, V. K. Pecharsky, B. Baumgartner, E. Wölfel, Mater. Sci. Forum 1993, 133-136, 335340.

[12] R. B. Von Dreele, A. C. Larson, GSAS Generalized Structure Analysis System, In: Neutron Scattering Center (Ed.: M. Lujan Jr.,), MS-H805, Los Alamos National Laboratory, Los Alamos, NM 87545, 2000.

Received: February 15, 2011 Published Online: April 13, 2011 